\title{
Childhood trauma, dissociation and self-harming behaviour: A pilot study
}

\author{
Gail Low and David Jones \\ Rampton Hospital, Retford, UK \\ Andrew MacLeod \\ Royal Holloway, University of London, UK \\ Mick Power \\ University of Edinburgh, UK \\ Conor Duggan* \\ University of Leicester, $U K$
}

\begin{abstract}
Objective: Childhood trauma is known to be an important antecedent in those who engage in deliberate self-harm (DSH). We aimed to explore the mediating mechanisms between childhood trauma and subsequent DSH in a sample of women detained in a high secure setting.
\end{abstract}

Method: From a previous incidence study into DSH, we subdivided a group of 50 women as follows: non-harmers $(N=13)$, infrequent harmers $(N=22)$ and frequent harmers $(N=15)$. These three groups were then compared on several measures believed to be associated with DSH.

Results: The frequency of DSH was related to low self-esteem, increased dissociation, anger (both inwardly and outwardly directed), impulsivity, and a history of sexual and physical abuse. When these variables were entered into a path analytic model exploring the relationship between childhood trauma and subsequent DSH, two paths emerged: one major path which linked childhood sexual abuse to DSH via increased dissociation and another, more minor association, linking childhood sexual abuse via reduced self-esteem.

Conclusion: This study shows a strong association between high levels of dissociation and an increased frequency of self-harming behaviour. This association is theoretically plausible and has therapeutic implications.

Deliberate self-harm (DSH) is a behaviour which is especially common among women who have experienced childhood sexual abuse (CSA) (Herman, Perry, \& van der Kolk, 
1989; Romans, Martin, Anderson, Herbison, \& Mullen, 1995). Van der Kolk, Perry and Herman (1991) conducted a prospective 4-year follow-up of self-harming behaviour exploring the relationship between childhood trauma, disrupted attachment and selfdestructive behaviour. They found that childhood sexual and physical abuse were highly predictive of subsequent self-cutting and suicide attempts. The link between CSA and DSH is thought to occur when there is a perceived re-enactment of a previous trauma (Miller, 1994) so that the behaviour is either an attempt to control a previously unmanageable situation or to provide a sense of relief (van der Kolk et al., 1991). Thus, for some, DSH becomes a way of coping with overwhelming affect and intrusive memories (Connors, 1996).

Increasing attention is also being given to the importance of dissociation as a mental mechanism in a range of psychiatric disturbance (van der Kolk \& Fisler, 1995). Dissociation consists of a disruption in the usually integrated functions of consciousness, memory, identity, or perception of the environment, which may be sudden or gradual, transient or chronic (American Psychiatric Association, 1994). It may arise from traumatic experiences and in turn produce long-term difficulties. Shalev, Peri, Canetti, and Schreiber (1996) have found, for instance, that high 'peri-traumatic' dissociation scores at the time of the trauma were predictive of the subsequent development of posttraumatic stress disorder. Findings such as this suggest that when individuals (especially children) are overwhelmed by an external stressor, they resort to denial or disengagemen $t$ (i.e. dissociate) as a way of coping. Although adaptive at the time, many traumatized individuals then continue to dissociate as a way of dealing with trauma-related memories and other stressful life experiences. Dissociation has been shown to link the experience of childhood abuse with subsequent self-harming behaviour (Chu \& Dill, 1990). In the van der Kolk et al. (1991) study, it was found that dissociation was specifically related to cutting. Other studies (for instance, Brodsky, Cloitre, \& Dulit, 1995; Zweig-Frank, Paris, \& Guzder, 1994) have failed to find an association between CSA and dissociation, although a link between dissociation and DSH was established as was a direct link between CSA and DSH.

In this investigation we sought to examine the pre-eminence of dissociation within the context of a range of other vulnerability factors which are also believed to be important in leading to DSH, and to determine if this was linked to earlier experiences of childhood trauma.

\section{Method}

\section{Participants}

We aimed to assess all mentally disordered women (excluding only those who were legally categorized as having mental impairment or severe mental impairment) detained at Rampton Hospital between March 1995 and January 1998. Rampton is one of three special hospitals within England and Wales, all of which treat mentally disordered patients in conditions of maximum security. All patients admitted to a special hospital are detained under the Mental Health Act and are legally categorized as having either mental illness, psychopathic disorder, mental impairment or severe mental impairment or a combination of these categories. These are legal, not diagnostic categories, and their correspondance to diagnostic categories, especially for psychopathic personality, is only modest. Despite this, we have chosen to use this legal categorization in this report as these were the data which were available to us. 


\section{Measures}

The following self-report questionnaires were administered: Self-Esteem Scale (Rosenberg, 1965). The Irritability, Depression and Anxiety Scale (Snaith, Constantopoulos, Jardine, \& McGuffin, 1978) which combines measures of anxiety, depression, outward and inward directed irritability. The Beck Hopelessness Scale (Beck, Weissman, Lester, \& Trexler, 1974), which is a 20-item true/false self-report measure assessing generalized hopelessness. The Dissociative Experiences Scale (Bernstein \& Putnam, 1986), a 28-item selfreport inventory measuring dissociative experiences including depersonalization and amnesia. The Suicide Ideation Scale (Beck, Kovacs, \& Weissman, 1979) which assesses self-reported suicidal thoughts. The impulsiveness subscale which is derived from the Impulsiveness (IVE) Questionnaire (Eysenck \& Eysenck, 1991). The Reasons for Living Inventory (Linehan, Goodstein, Neilsen, \& Chiles, 1983) which was developed to identify the reasons individuals gave for not killing themselves when the thoughts of suicide occurred to them. There are six subscales: survival and coping beliefs, responsibility to the family, fear of suicide, fear of social disapproval, moral obligation and child related concerns. It has been found that low scores characterize those prone to self-harming behaviour. Finally, we used the Traumatic Antecedents Questionnaire (TAQ; Herman et al., 1989) to assess any early experiences of childhood trauma. This is by direct interview and inquires about childhood experiences of physical and sexual abuse, physical and emotional neglect, early separations and losses from significant persons and domestic chaos. Of the 50 patients assessed, 29 agreed to be interviewed with the Traumatic Antecedents Questionnaire. In cases where it was not possible to obtain this information directly, we obtained relevant data from the extensive case notes and reports compiled on each patient and their named keyworker and used this to rate the patient on the presence or absence of the relevant variable. We restricted the evaluation of childhood traumatic data in this report to accounts of childhood sexual or physical abuse because we believed that only these data could be collected accurately from these secondary sources. This enabled us to include all 50 women in this paper. Rating the TAQ was conducted blind to the history of the patient's DSH.

\section{Incidence of DSH}

From a previous 30-month incidence study using the same sample (Low, Terry, Duggan, MacLeod, \& Power, 1997), we subdivided the group as follows: non-harmers $(N=13)$ (i.e. without any DSH within the incidence study period), infrequent harmers $(N=22)$ (those who harmed themselves less than once a month), and frequent harmers $(N=15)$ (those whose incidence rate of DSH was greater than once per month). The self-harming behaviour was generally mild and mainly managed by nursing staff (Low et al., 1997).

\section{Statistical analysis}

This comprised a one-way ANOVA with Least Significant Difference tests of significance to test $a$ priori hypotheses. In order to model the possible relationships between past and current factors that may be related to self-harm, a number of path analyses were carried out using key variables from the initial analyses (using EQS Version 5; Bentler \& Wu, 1995). The local Ethics Committee granted approval for the project.

\section{Results}

Of the 83 women who were 'within scope' for the study, $50(60 \%)$ consented to take part, $12(14 \%)$ refused and $21(25 \%)$ were unable to participate because of severe psychoses. We compared those who agreed to participat e ('consentors') with those who either refused or were unable to participate ('refusers') across the following variables to determine the representativenes $s$ of the former. Those who consented were younger: the mean ages (SD) for the 'consentors' and 'refusers' respectively were 32.04 (8.2) and 41.9 (11.6) years ( $\mathrm{t}$ $(81)=4.55, p<.001)$; ranges (and medians) for 'consentors' and 'refusers' were 18-51 (31) and 17-62 (43) years respectively. They had also spent less time in hospital: the mean lengths of stay in the hospital for the 'consentors' and 'refusers' were 70.5 (46.5) and 
135.3 (98.7) months respectively $(\mathrm{t}(81)=4.3, p<.001)$; ranges (and medians) for 'consentors' and 'refusers' were 3-177 (62.5) and 0.5-358 (121) months respectively. Having excluded those with a dual legal classification, a larger proportion of the 'consentors' were classified as having 'psychopathic disorder' while the 'refusers' were predominantly mentally ill (chi-squared $(81=6.05, p=.01)$. In summary, those women who refused or were unable to participate in the study were older, had spent a longer period in hospital and were more likely to be mentally ill.

Those who agreed to participate (i.e. the 'consentors') were subdivided by their frequency of DSH from the incidence study into three groups and these were also compared across the same variables (Table 1). Those who frequently self-harmed tended to be younger and to have spent longer in hospital but in neither case were these differences statistically significant. These variables were normally distributed within the sample. Those who frequently self-harmed were more likely to carry the Psychopathic Disorder legal designation.

Table 1. Comparison of assessment sample groups (with percentage of total population in parentheses), according to age, length of stay, and Mental Health Act (1983) Classification

\begin{tabular}{|c|c|c|c|c|c|c|c|c|c|c|c|c|}
\hline \multirow[b]{2}{*}{ Group } & \multirow[b]{2}{*}{$N$} & \multirow[b]{2}{*}{$\%$} & \multicolumn{2}{|c|}{$\begin{array}{c}\text { Age } \\
N=50\end{array}$} & \multicolumn{2}{|c|}{$\begin{array}{l}\text { Length } \\
\text { of stay } \\
\text { (Years) }\end{array}$} & \multicolumn{2}{|c|}{$\begin{array}{c}\text { Mental } \\
\text { illness }\end{array}$} & \multicolumn{2}{|c|}{$\begin{array}{l}\text { Psycho- } \\
\text { pathic } \\
\text { disorder }\end{array}$} & \multicolumn{2}{|c|}{$\begin{array}{c}\text { Dual } \\
\text { classifica- } \\
\text { tion }\end{array}$} \\
\hline & & & $M$ & $\mathrm{SD}$ & $M$ & $\mathrm{SD}$ & $N$ & $\%$ & $N$ & $\%$ & $N$ & $\%$ \\
\hline Non-harmers & 13 & $(43.3)$ & 35 & 9.5 & 4.2 & 4.2 & 5 & $(27.7)$ & 6 & $(85.7)$ & 1 & $(40)$ \\
\hline Infrequent harmers & 22 & $(61.1)$ & 32 & 5.9 & 5.9 & 3.2 & 11 & $(57.8)$ & 8 & $(61.5)$ & 3 & $(75)$ \\
\hline Frequent harmers & 15 & $(88.2)$ & 30 & 9.5 & 7.1 & 4.3 & 2 & $(100)$ & 10 & $(83.3)$ & 3 & $(100)$ \\
\hline Total & 50 & $(60.2)$ & 32 & 8.2 & 5.9 & 3.9 & 18 & (46) & 24 & $(75)$ & 8 & $(66.6)$ \\
\hline
\end{tabular}

Table 2 compares the three groups on the range of variables believed to tap the vulnerability to DSH. None of the three groups reported significant depressive symptoms on the Beck Depression Inventory. There was a non-statistically significant reduction in self-esteem and non-statistically significant increase in hopelessness with increasing frequency of self-harm. The frequent harmers compared with the non-harmers reported higher levels of anxiety, of outwardly directed irritability and of suicidal ideation. For inwardly directed irritability, the frequent harmers had significantly higher scores as compared with the other two groups whereas for impulsivity both the harming groups scored significantly higher compared with the non-harming group. The only measure in which all three groups differed from one another was dissociation with the frequent harmers having the highest levels and the non-harmers, the lowest.

The only differences to emerge between the groups in the Reasons for Living Inventory were on the subscales of survival and coping beliefs and fear of suicide (Table 3). Here, the frequent harming group had significantly fewer survival and coping beliefs as compared with both the infrequent harmers and the non-harmers. On fear of suicide, the frequent harmers scored significantly lower than the infrequent harmers. 


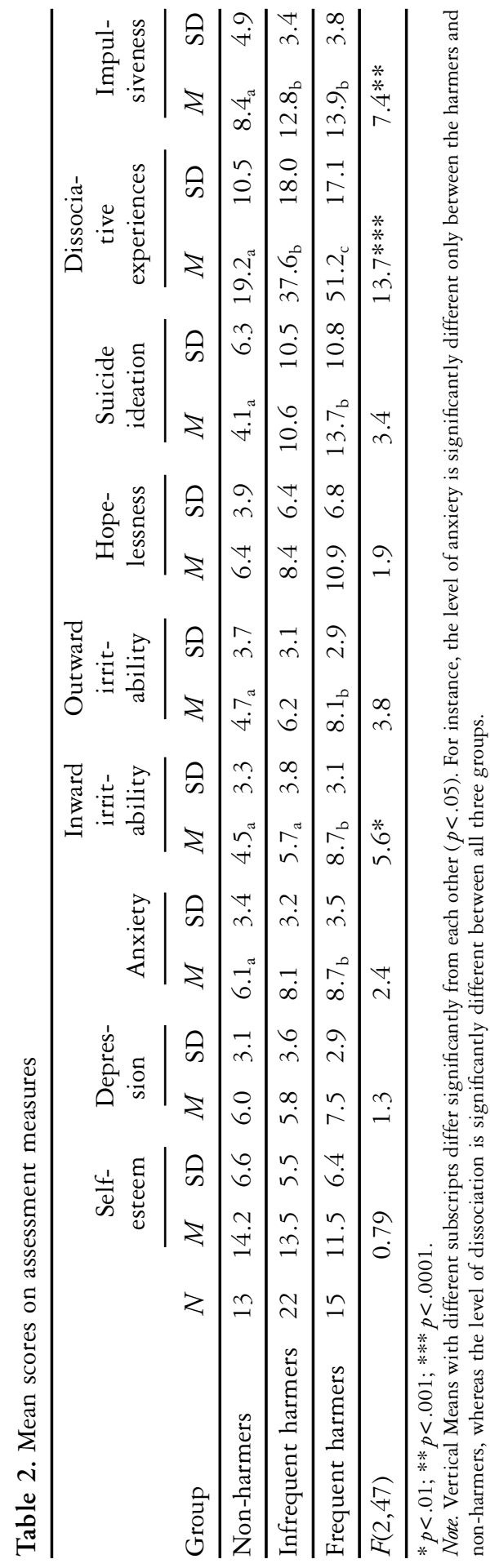


Table 3. Mean scores on the Reasons for Living Inventory

\begin{tabular}{|c|c|c|c|c|c|c|c|c|c|c|c|c|c|}
\hline \multirow[b]{2}{*}{ Group } & \multirow[b]{2}{*}{$N$} & \multicolumn{2}{|c|}{$\begin{array}{l}\text { Survival } \\
\text { and } \\
\text { coping } \\
\text { beliefs }\end{array}$} & \multicolumn{2}{|c|}{$\begin{array}{c}\text { Moral } \\
\text { obligation }\end{array}$} & \multicolumn{2}{|c|}{$\begin{array}{l}\text { Respons- } \\
\text { ibility } \\
\text { to } \\
\text { family }\end{array}$} & \multicolumn{2}{|c|}{$\begin{array}{c}\text { Fear of } \\
\text { social } \\
\text { dis- } \\
\text { approval }\end{array}$} & \multicolumn{2}{|c|}{$\begin{array}{l}\text { Fear of } \\
\text { suicide }\end{array}$} & \multicolumn{2}{|c|}{$\begin{array}{l}\text { Child } \\
\text { related } \\
\text { concerns }\end{array}$} \\
\hline & & $M$ & SD & $M$ & SD & $M$ & SD & $M$ & SD & $M$ & $\mathrm{SD}$ & $M$ & SD \\
\hline Non-harmers & 13 & $4.4_{a}$ & 1.3 & 3.4 & 1.7 & 4.1 & 1.5 & 3.3 & 1.6 & 3.3 & 1.5 & 3.7 & 2.2 \\
\hline Infrequent harmers & 17 & $4.3 \mathrm{a}$ & 1.5 & 3.4 & 1.4 & 4.4 & 1.6 & 3.4 & 1.8 & $3.7_{\mathrm{a}}$ & 1.4 & 3.2 & 2.3 \\
\hline Frequent harmers & 14 & $3.2_{\mathrm{b}}$ & 1.3 & 2.6 & 1.1 & 4.2 & 1.6 & 3.1 & 1.6 & $2.7_{\mathrm{b}}$ & 0.8 & 2.5 & 1.9 \\
\hline$F(2,41)$ & 44 & $3.4^{*}$ & & 1.4 & & 0.1 & & 0.1 & & $2.2 *$ & & 1.0 & \\
\hline
\end{tabular}

$* p<.01$.

Note. Vertical Means with different subscripts differ significantly from each other $(p<.05)$. For instance, the level of anxiety is significantly different only between the harmers and non-harmers, whereas the level of dissociation is significantly different between all three groups.

On the Childhood Traumatic Antecedents Questionnaire, the percentages with a history of childhood sexual abuse among the non-harmers, infrequent harmers and frequent harmers were $46 \%, 55 \%$ and $80 \%$, respectively. For a history of physical abuse, a similar trend emerged, although the percentages of $30 \%, 50 \%$ and $60 \%$ were lower as compared with history of sexual abuse.

\section{Path analyses}

The path analyses used the variables in the previous univariate statistics. Table 4 shows a number of zero-order correlations for the key variables that were eventually used. The zero-order correlations shown are mostly significant, or close to significance, although it must be noted that general structural equation models can occasionally 'unmask' the effect of a variable, in addition to eliminating the effects of variables that have substantial intercorrelations.

Table 4. Zero-order correlations for the main variables used in the path analyses. These show polyserial or polychoric correlations where categorical variables are involved

\begin{tabular}{lccc}
\hline & Sexual abuse & $\begin{array}{l}\text { Dissociative } \\
\text { experiences }\end{array}$ & Self-esteem \\
\hline Dissociative experiences & 0.274 & & \\
Self-esteem & -0.298 & -0.208 (n.s.) & -0.199 (n.s.) \\
Self-harm & 0.367 & 0.652 & - \\
\hline
\end{tabular}

Note. Values are significant at $p<0.05$ or better unless stated otherwise (n.s.).

Based on previous conceptual and empirical findings, the path analytic model shown in Fig. 1 was first tested. This model incorporates a temporal causal effect in moving from left to right in the diagram; that is, because of temporal precedence sexual abuse is represented as causing self-harm. The model includes two paths from sexual abuse to selfharm. The first path is the proposal that dissociative experiences may be proximally 
associated with self-harm (as shown in Table 2), but the tendency to dissociation in turn is caused by sexual abuse. This path is clearly significant, as shown in Fig. 1a. However, it is also necessary to test whether or not there are other potential causal paths between sexual abuse and self-harm that occur via mechanism s other than dissociation. The second direct path from sexual abuse to self-harm (see Fig. 1a) suggests that there is one (or more) additional routes because this path is also significant.

There were a number of candidate variables within our data-set that could provide possible mechanisms for the effect of early abuse on current self-harm. Variables that were tested one at a time included the variables shown in Table 2 that either were significant or that approached significance in distinguishing harmers and non-harmers. Analyses of the type shown in Fig. 1b showed that Self-Esteem and Inward and Outward Irritability all provided significant pathways. In order to help decide between different possible models, a number of 'degree of fit' indices are provided by structural equation programs such as EQS; a significant improvement in 'fit' for one model over another can be used therefore to select between different models when there are no other criteria on which to select between them (e.g. Bentler \& Wu, 1995). From the various models that were tested, the best fitting model was that shown in Fig. 1b, which included the self-esteem variable. The corrected Comparative Fit Index (CCFI) was 1.00 (the maximum level of fit) and the corrected chi-square value was 1.287 with 2 degrees of freedom which is non-significant

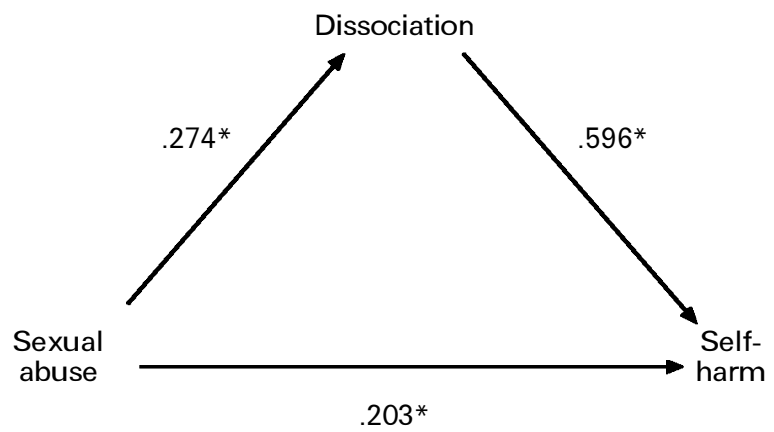

Figure 1a. Path analysis showing the impact of early sexual abuse on current self-harm. Values on paths indicated by $*$ are standardized regression coefficients significant at $p<.05$.

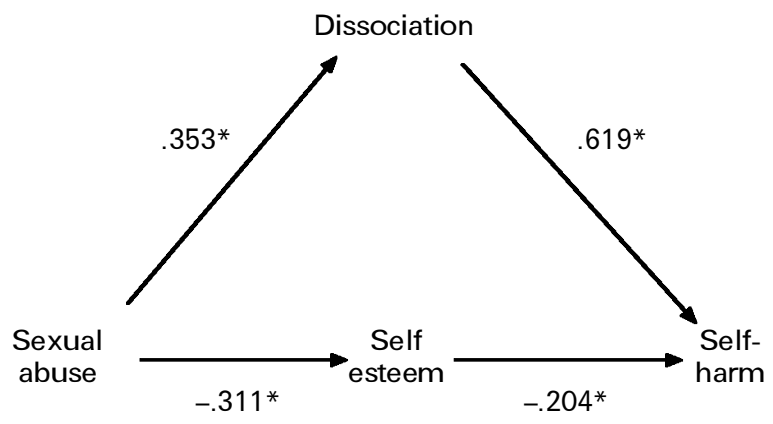

Figure 1b. Path analysis showing the 'best fitting' equation for the impact of sexual abuse on current selfharm. Values on paths indicated by $*$ are standardized regression coefficients significant at $p<.05$. 
(in terms of model fitting the lower the chi-square value, the better the fit). The comparable values for Inward Irritability were, by contrast, CCFI $=0.972$, corrected chi-square $(2)=13.92, p<.001$. In summary, therefore, the path analyses suggested that there is a clear link between early sexual abuse and later self-harm. One route occurs via an increased likelihood of dissociative experiences, and a second route occurs via a general lowering of self-esteem which is also likely to lead to self-harm. Finally, our analyses showed that these effects were linked specifically with sexual abuse in this population; when the analyses were repeated with just physical abuse, or with a summary score for total abuse, one or more of the pathways became non-significant.

\section{Discussion}

This study examined the association between childhood trauma, current levels of dissociation and deliberate self-harm. There were two main findings. First, patients who engaged in self-harming behaviour had a number of expected characteristic s on selfreport including higher inward and outward directed irritability, impulsiveness, suicide ideation together with fewer survival and coping beliefs and lower self-esteem. However, the groups of patients were best separated by their score on the Dissociative Experiences Scale with the frequent harmers scoring highest. Second, childhood sexual abuse was linked to current DSH both by dissociation and also another weaker link, possibly by reduced self-esteem.

This study adds to an increasing body of empirical evidence for the importance of dissociation as a mental mechanism, which is likely to lead to deliberate self-harm. Although dissociation is often precipitated by intolerable affect, the experience of dissociation with its attendant fragmentation may itself be aversive so that self-harming behaviour then becomes a way of coping with dissociation (Favazza \& Conterio, 1989). Thus, there is a plausible link between some perceived re-enactment of the trauma, an intolerable affect, dissociation and self-harming behaviour (Leibenluft, Gardner, \& Cowdry, 1987; Power \& Dalgleish, 1997).

This renewed focus on dissociation has important clinical implications. It implies, for instance, that traumatic memories are not actively extruded from consciousness because of repression, rather, the mental capacity is weakened by the traumatic experience so that the integration into conscious awareness is impaired. Hence, the stabilization of the patient through control and mastery of the traumatic memories and associated affect is a necessary prelude to exploration of the nature of the trauma. Indeed, dealing with dissociation is believed to be the crucial area on which intervention should be focused (Brodsky, Cloitre, \& Duit, 1995) and the effectivenes s of modern approaches (for instance, Dialectical Behavioral Therapy; Linehan, 1993) may rest upon the degree to which dissociation is reduced.

In contrast to the strength of the proximal relationship between dissociation and DSH, the links between dissociation and the distant antecedent variable (childhood trauma) is less well established in the literature. This is not unexpected, given the long time lag between the experience of childhood trauma and the assessment of dissociation, with a welter of intervening variables in between. The reason for our positive finding may be that, for the majority of the women in this study, the experience of childhood abuse was sustained and brutalizing and hence one might expect to find an association with a 
defensive mechanis m of denial in this sample. It is clear, however, that childhood trauma may result in several different outcomes only one of which may be dissociation (Brodsky et al., 1995). Our data show evidence for this in that there was an additional pathway to dissociation between CSA and adult DSH. This was partially explained by low selfesteem in those who had suffered CSA. Indeed, our finding is consistent with the earlier suggestion of Finkelhor (1988) that CSA could have long-term effects through mechanisms other than dissociation and one of these was through reduced self-esteem. This suggestion received support from this study although admittedly the link between CSA and self-harm through low self-esteem was weak.

This study had limitations. First, our sample consisted of women detained in high security, which means that they were already highly selected and this raises a question about the generalizabilit y of the findings. In addition, although we tried to study all such women, we managed to obtain data on only $60 \%$, and these were younger and had spent less time in hospital. Second, we used multiple measures, so it may be possible that some of the differences arose by chance. Third, we restricted the subdivision of the group to self-harming behaviour over the previous 30 months rather than on lifetime rates. Fourth, we were not able to obtain a diagnosis relying on a legal classification; however, previous studies of this group have shown that the most common diagnosis among women with a psychopathic disorder classification is that of borderline personality disorder (Coid \& Dill, 1992). Finally, the use of the path analytic approach ought ideally to include more participants .

Despite studying a highly selected group of women, what was striking was that the frequent self-harming group had many of the features one might expect to find in a similar but not detained group of women. An additional advantage of this study was that we were able to obtain observed measures of self-harm rather than relying on self-report. A subgroup of these women had features which are known to make them prone to selfharming behaviour and hence would make them a suitable group to examine the associations between these variables.

\section{Acknowledgements}

This study was supported from grants from the High Security Psychiatric Services Commissioning Board (G. Low) and from Rampton Hospital (D. Jones). The authors would also like to thank the patients and staff at Rampton Hospital who made this project possible.

\section{References}

American Psychiatric Association. (1994). Diagnostic and statistical manual of mental disorders (4th ed.). Washington, DC: American Psychiatric Association.

Beck, A. T., Kovacs, M., \& Weissman, A. (1979). Assessment of suicidal intention: The scale for suicide ideation. Journal of Consulting and Clinical Psychology, 47, 343-352.

Beck, A. T., Weissman, A., Lester, D., \& Trexler, L. (1974). The measurement of pessimism: The Hopelessness Scale. Journal of Consulting and Clinical Psychology, 42, 861-865.

Bentler, P. M., \& Wu, E. J. C. (1995). ESQ for Windows Users Guide. Ercino Multivariate Software, Inc. California.

Bernstein, E. M., \& Putnam, F. W. (1986). Development, reliability, and validity of a dissociation scale. Journal of Nervous and Mental Disease, 174, 727-735. 
Brodsky, B., Cloitre, M., \& Dulit, R. (1995). Relationship of dissociation to self-mutilation and childhood abuse in borderline personality disorder. American Journal of Psychiatry, 152, 1788-1792.

Chu, J. A., \& Dill, D. L. (1990). Dissociative symptoms in relation to childhood physical and sexual abuse. American Journal of Psychiatry, 147, 887-892.

Coid, J. A., \& Dill, D. L. (1992). Self-mutilation in female remanded prisoners II: A Cluster analytic approach towards identification of a behavioural syndrome. Criminal Behaviour and Mental Health, 2, 1-14.

Connors, R. (1996). Self-injury in trauma survivors: 1. Functions and meanings. American Journal of Orthopsychiatry, 66, 197-206.

Eysenck, H. J., \& Eysenck, S. B. G. (1991). Manual of the Eysenck Personality Scales (EPS Adult). London, Sydney, Auckland: Hodder \& Stoughton.

Favazza, A. R., \& Conterio, K. (1989). Female habitual self-mutilators. Acta Psychiatrica Scandinavica, 79, 283-289.

Finkelhor, D. (1988). The trauma of child sexual abuse: Two models. In G. E. Wyatt \& C. J. Powell (Eds.), Lasting effects of child sexual abuse (pp. 61-82). Beverly Hills, CA: Sage.

Herman, J. L., Perry, J. C., \& van der Kolk, B. A. (1989). Childhood trauma in borderline personality disorder. American Journal of Psychiatry, 146, 490-495.

Leibenluft, E., Gardner, D., \& Cowdry, R. (1987). The inner experience of the borderline self-mutilator. Journal of Personality Disorders, 1, 317-324.

Linehan, M. M. (1993). Cognitive-behavioral treatment of borderline personality disorder. New York: Guilford.

Linehan, M. M., Goodstein, J. L., Nielsen, S. L., \& Chiles, J. A. (1983). Reasons for staying alive when you are thinking of killing yourself: The reasons for living inventory. Journal of Consulting and Clinical Psychology, 51, 276-286.

Low, G., Terry, G., Duggan, C., MacLeod, A., \& Power, M. (1997). Deliberate self-harm among female patients at a special hospital: An incidence study. Health Trends, 29, 6-9.

Miller, D. (1994). Women who hurt themselves. New York: Harper Collins.

Power, M., \& Dalgleish, T. (1997). Cognition and emotion: From order to disorder. Hove: Psychology Press.

Romans, S. E., Martin, J. L., Anderson, J. C., Herbison, G. P., \& Mullen, P. E. (1995). Sexual abuse in childhood and deliberate self-harm. American Journal of Psychiatry, 152, 1336-1342.

Rosenberg, M. (1965). Society and the adolescent self image. Princeton, NJ: Princeton University Press.

Shalev, A. Y., Peri, T. L., Canetti, L., Schreiber, S. (1996). Predictors of PTSD in injured Trauma Survivors: A Prospective Study. American Journal of Psychiatry 153(2), 219-225.

Snaith, R. P., Constantopoulos, A. A., Jardine, M. Y., \& McGuffin, P. (1978). A clinical scale for the self-assessment of irritability. British Journal of Psychiatry, 132, 164-171.

van der Kolk, B. A., \& Fisler, R. (1995). Dissociation and the fragmentary nature of traumatic memories: Overview and exploratory study. Journal of Traumatic Stress, 8, 505-525.

van der Kolk, B. A., Perry, J. C., \& Herman, J. L. (1991). Childhood origins of self-destructive behavior. American Journal of Psychiatry, 148, 1665-1671.

Zweig-Frank, H., Paris, J., \& Guzder, J. (1994). Psychological risk factors for dissociation and selfmutilation in female patients with borderline personality disorder. Canadian Journal of Psychiatry, 39, 259-263. 